\title{
Numerical analysis of proposed tubular perfobond shear connector
}

\author{
K.L.B. Souza, A.T. Silva, P.C.G.S. Vellasco \& M.C. Rodrigues \\ State University of Rio de Janeiro, Rio de Janeiro, Brazil \\ J. Henriques \\ Hasselt University, Hasselt, Belgium
}

\begin{abstract}
The most common means for connection between steel and concrete is mechanical, usually through shear connectors. Currently, numerous shear connectors are available to designers which have been subject of study in the past decades. Eurocode 4 prescribes a minimum characteristic slip capacity for the connector to be considered as ductile. Thus, this paper proposes an alternative tubular perfobond shear connector encompassing the resistance of the conventional Perfobond and providing the required ductility prescribed by the code. The study has been conducted using the finite element method through push-out tests to determine the connector resistance and slip capacity. The influences of the most relevant parameters and properties were determined. Due to the lack of results on the tubular perfobond connectors, the experimental results on Perfobond connectors available in the literature were previously used to validate the numerical model. The proposed connector has presented a satisfactory performance and could be considered viable.
\end{abstract}

\section{INTRODUCTION}

The composite structure is an innovative, efficient and economical structural solution that reveals the human capacity for technological innovation through the use of new materials and the conception of optimized structural systems. The connection between the materials, transfer of efforts and the shear strength along the steel-concrete contact surfaces can be achieved by mechanical means such as shear connectors. The shear connector confers the interaction between steel and concrete, transmitting forces from one material to the other, enabling them to work in a solid and monolithic way to resist the solicitations. Gu et al. (2019) consider shear connectors as the key element of the composite structure, where they make the composite behaviour happen, minimizing the slip between the materials.

Many shear connectors have been developed in the last decades, such as stud bolt, C-profiles, U-profiles, Crestbond, Perfobond, among others. The stud is standardized by Eurocode 4 (2005), and it is the most commonly used due to the practicality and quickness of its installation process. Its disadvantage is related to low resistance to fatigue and the need for electricity to installation. These disadvantages led to the necessity of developing alternative connectors, which can be produced at the construction site. According to Bezerra et al. (2018), these new connectors can encourage the popularization of composite construction. The U-profile connector was one of those that became widely used due to stud limitation. This connector is easy to manufacture and weld, but its web has a relatively small stiffness, allowing it to suffer great deformations.

Due to the limitations, new alternative connectors were created. In this process, the Perfobond connector was conceived. It has stood out from the others, and it is known to have 
greater rigidity and resistance than studs. However, it has low slip capacity, which often characterizes it as a non-ductile connector.

Therefore, there is a need for an alternative connector to Perfobond that can present excellent resistance, as well as Perfobond, and to achieve adequate slip capacity, as recommended by Eurocode 4 (2005). Thus, from this need, a tubular shear connector is proposed. It is expected that a tubular cross-section can optimize the connector performance, leading to satisfactory resistance and ductility. Therefore, to evaluate the proposed connector, some parameters are studied, and a brief numerical study is performed and presented.

\section{VALIDATION OF THE NUMERICAL SIMULATION OF PERFOBOND CONNECTORS}

\subsection{Reference push-out tests on Perfobond connectors}

There is no result of a connector similar to the tubular; thus, a validation of the numerical modelling will be carried out from the results of the Perfobond connectors of Vianna et al. (2009). Their research covered Perfobond and T-Perfobond connectors. For this validation, the Perfobond connector with two holes (EX-P-2H-120) was chosen. The dimensions and geometries of the specimen in question can be found in Vianna et al. (2009).

\subsection{Development of the numerical model}

The study was performed in Abaqus 6.14 (2010). The explicit solver was used in the nonlinear numerical analysis conducted, which encompasses complex contact interactions, the nonlinearity of materials and large deformations. Other authors such as Gu et al. (2019) have used this solver previously for similar numerical simulations. The loading process was quasi-static, and its ratio was monitored to avoid dynamic effects. During the analysis, the kinetic energy was kept between $5 \%$ and $10 \%$ of the internal energy to guarantee a quasi-static analysis.

\subsubsection{Geometry, loading and boundary conditions}

All components were modelled with solid elements and are shown in Figure 1. As in the experimental test, a loading was applied from the introduction of an axial displacement on the "I" profile section upper face. About the boundary conditions, displacement restrictions have been applied in the three directions of the global axes at the slabs bases. Both have been applied to the reference points belonging to the multi-point constraints (MPCs) (Figure 1c).

\subsubsection{Material modelling}

The modelling of the materials considered the properties used by Vianna et al. (2009). The steel employed were S355, S275 and S500 for the connector, the beam and the reinforcement,

a)

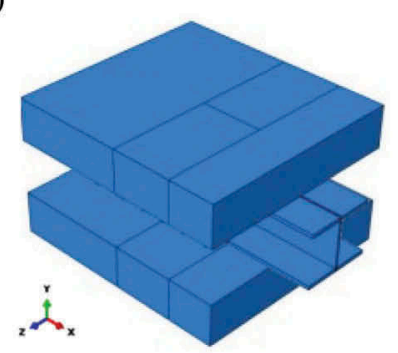

b)

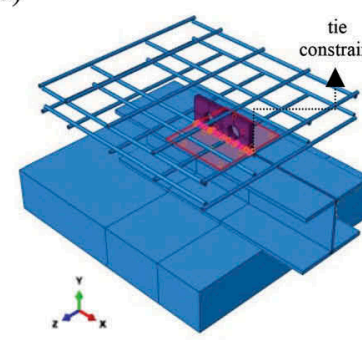

c)

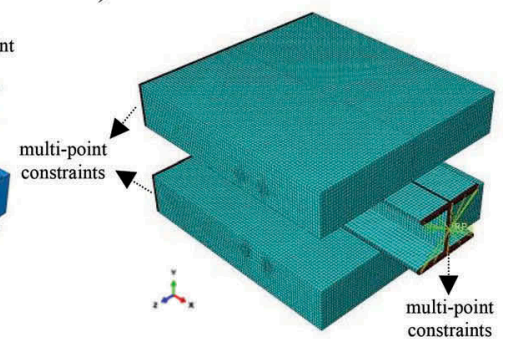

Figure 1. Geometry, load, boundary conditions, tie constraints and mesh of Perfobond numerical model. a) Push-out test model layout, b) Tie constraint, c) Mesh and details of load and boundary conditions at MPCs. 
respectively. For the modelling of the beam and reinforcement, an elastic perfectly plastic stress-strain model was chosen. Regarding the shear connector, it was modelled following the quadrilinear stress-strain law proposed by Yun and Gardner (2017).

The concrete has $f_{c m}$ equal to $28 \mathrm{MPa}$ and $52 \mathrm{MPa}$. A concrete damaged plasticity model (CDP) was chosen to characterize the concrete behaviour. To use this package, it is necessary to inform five plastic parameters and the behaviour under compression and tension. The parameters, dilation angle $(\psi)$, eccentricity $(\varepsilon)$, the ratio of biaxial to uniaxial compressive strength $\left(f_{b o} / f_{c o}\right)$, the ratio of the second stress invariant on the tension meridian to that on the compressive $(\mathrm{K})$ and a viscosity parameter $(\mu)$ are taken as $38,0.1,1.16,0.667$ e 0 , respectively.

The constitutive law proposed by Pavlovic (2013) was adopted to characterize the behaviour of concrete under compression in terms of a stress-strain ratio. About the damage model, Genikomsou and Polak (2015) consider that concrete under compression only loses stiffness after reaching its resistance, $f_{c m}$. All parameters necessary can be found in Pavlovic (2013) and Genikomsou and Polak (2015). The bilinear tensile behaviour recommended by CEB (2010) was used through the stress-crack opening relation. Similar to the compression behaviour, the authors also consider that concrete only cracks after reaching its resistance, $f_{\text {ctm }}$. More details about these formulations can be found in CEB (2010) and Genikomsou and Polak (2015).

\subsubsection{Constraints and contact interactions}

The interaction between the reinforcement bars and the concrete was applied through the embedded constraint. To simulate the weld between the shear connector and the steel beam, the tie constraint was applied in a manner that keeps the faces together during the entire numerical simulation (Figure 1b). Regarding the contact properties, the normal hard contact behaviour was applied to avoid overlapping between the parts during the simulation. A tangential behaviour was also assumed during the analysis with a coefficient of friction equal to 0.15 .

\subsubsection{Meshes}

A mesh (Figure 1c) was adopted with an overall size of $5 \mathrm{~mm}$ e $24 \mathrm{~mm}$ for the shear connector and reinforcement bars, respectively. The slab and the steel beam mesh adopted an $8 \mathrm{~mm}$ element size. All the components of the model were discretized with 3D elements of type C3D8R.

\subsection{Validation of the numerical model}

The shear connection capacity obtained from the experimental tests (EX-P-2H-120-28MPa and EX-P-2H-120-52MPa) and finite element analysis (NM-P-2H-120-28MPa and NM-P-2H-120$52 \mathrm{MPa}$ ), as well as the load-slip ratio of the specimens, are exhibited in Table 1 and Figure 2.

Analyzing the results, it can be seen that a satisfactory agreement was reached between the two results, mainly to the model with $28 \mathrm{MPa}$. It could be observed that the connector numerical model with $28 \mathrm{MPa}$ presented resistance $4 \%$ higher when compared to the experimental one. The $52 \mathrm{MPa}$ model was $10 \%$ more resistant than the experimental connector model. However, when comparing the slip capacity of the connector, the $52 \mathrm{MPa}$ numerical model was the most similar to the experimental one. This fact can also be proved when observing the post-peak behaviour of the load-slip ratio. NM-P-2H-120-28MPa presented initial stiffness similar to the experimental one. After reaching its resistance, the numerical model lost stiffness faster, which justifies the lower slip capacity. NM-P-2H-120-52MPa lost stiffness slower in the post-peak segment,

Table 1. Comparison from experimental and FEA results.

\begin{tabular}{|c|c|c|c|c|c|c|}
\hline & $P_{\text {EXP }}$ & $P_{\mathrm{NUM}}$ & $P_{N U M}$ & $\delta u_{E X P}$ & $\delta u_{N U M}$ & $\delta_{N U M}$ \\
\hline Connector & $\mathrm{kN}$ & $\mathrm{kN}$ & $P_{E X P}$ & $\mathrm{~mm}$ & $\mathrm{~mm}$ & $\delta_{E X P}$ \\
\hline $\mathrm{P}-2 \mathrm{H}-120-28 \mathrm{MPa}$ & 329.75 & 342.94 & 1.04 & 7.77 & 4.35 & 0.56 \\
\hline $\mathrm{P}-2 \mathrm{H}-120-52 \mathrm{MPa}$ & 394.20 & 434.47 & 1.10 & 7.80 & 8.92 & 1.14 \\
\hline
\end{tabular}


a)

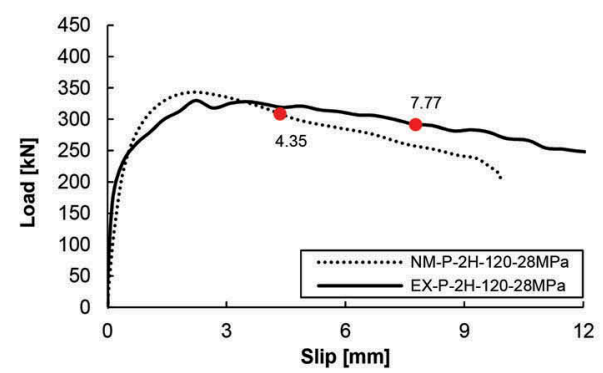

b)

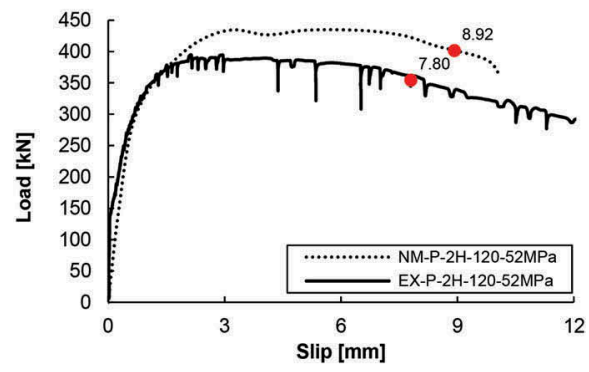

Figure 2. Comparison of experimental and FEA results. a) NM-P-2H-120-28MPa and EX-P-2H-120$28 \mathrm{MPa}, \mathrm{b}) \mathrm{NM}-\mathrm{P}-2 \mathrm{H}-120-52 \mathrm{MPa}$ and EX-P-2H-120-52MPa.

resembling the experimental despite the resistance difference. Therefore, the $28 \mathrm{MPa}$ model was validated in terms of peak load and the $52 \mathrm{MPa}$ in terms of post-peak behaviour.

\section{NUMERICAL ASSESSMENT OF THE POTENTIAL OF THE NEW TUBULAR PERFOBOND SHEAR CONNECTOR}

\section{$3.1 \quad$ Numerical modelling}

The numerical modelling previously presented was applied in the tubular connector study, including material properties, constraints, contacts, interfaces, boundary conditions, mesh, among others. The tubular connector has been studied as without holes, with two holes and with two holes and rebar (Figure 3a-c). To minimize computational cost, only a quarter model was modelled, using double symmetry restrictions. It is possible to observe in Figure $3 \mathrm{~d}$, the surface 1 (X-Z plan) was set as symmetrical in the $\mathrm{Y}$-axis with all nodes on this surface restricted from moving in the $\mathrm{Y}$ direction. Surface $2(\mathrm{X}-\mathrm{Y})$ has been imposed as symmetrical in the direction in the $\mathrm{Y}$-axis, restricting its nodes to the movement in this direction. The width of Perfobond was maintained to a tubular connector to allow comparisons. Figure 3e presents the tie constraint that links the surfaces between the tubular connector and the steel beam.

Concerning the nomenclature of the models, the TP index indicates tubular perfobond. The $\mathrm{S}$ indicates square section $70 \times 70 \times 3.6 \mathrm{~mm}$ while the $\mathrm{R}$ indicates rectangular section $70 \times 50 \times 3.6 \mathrm{~mm}$. NH denotes that the connector has no holes, $2 \mathrm{H}$ denotes that it has two holes and $2 \mathrm{H}-\mathrm{R}$ denotes that it has two holes and rebar. $28 \mathrm{MPa}$ and $52 \mathrm{MPa}$ indicate concrete resistance. For example, TP-S-2H-R-28MPa refers to a square section tubular connector model with two holes, rebar and concrete with $f_{c m} 28 \mathrm{MPa}$.

a)

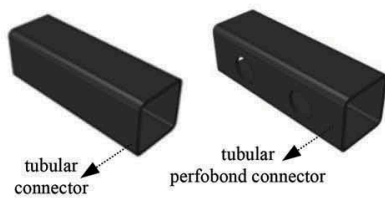

c)

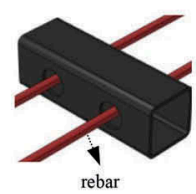

d)

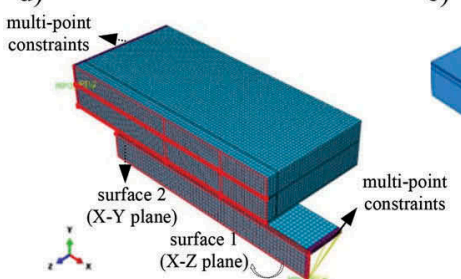

e)

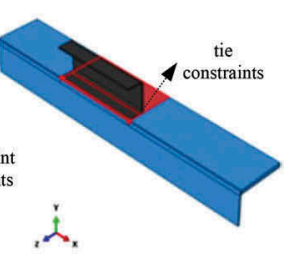

Figure 3. Tubular perfobond connector model. a) Without holes, b) With two holes, c) With two holes and rebar, d) Symmetric surfaces, multi-point constraints and mesh, e) Tie constraint. 


\subsection{Parametric study}

As presented, two concrete compressive strength $\left(f_{c m}\right)$ were studied to evaluate their influence on the connector performance. The influence of the hole and the rebar, as well as the connector cross-section, was also evaluated. Figure 4 and Figure 5 present the results in regards to the load-slip ratio and the parameters influence, respectively. Table 2 presents the results obtained in terms of maximum $(P)$ and characteristic resistance $\left(P_{r k}\right)$, shear rigidity $\left(K_{s}\right)$, slip capacity $\left(\delta_{u}\right.$ and $\left.\delta_{u k}\right)$, ductility rating and failure mode. Except for the shear rigidity and failure mode, all results were taken according to Eurocode 4 (2005). The rigidity was defined according to Chen et al (2011) and the failure mode was determined according to the evolution of the degradation.

Analyzing the models with both concrete strengths, it can be seen that the connector with the largest transversal area presents the greatest resistance for all the conditions studied. However, the increase in the cross-sectional area provided only slight increases in resistance, ranging from $3 \%$ to $5 \%$. The use of the hole and rebar conferred a resistance increase for the models with $28 \mathrm{MPa}$. For $52 \mathrm{MPa}$, it did not influence the resistance due to the excessive connector yield. For all models, it led to the connector peak load occur to higher slip values, contributing to ductility.

The increase in the concrete strength resulted in a significant improvement in the shear connector resistance for the different cases studied, ranging from $16 \%$ to $29 \%$. There was an expressive increase in the slip capacity of the tubular shear connector due to the rise in the $f_{\mathrm{cm}}$, ranging from $18 \%$ to $137 \%$. Briefly, the concrete strength influenced in a more significant way the square section connector concerning the shear strength and the rectangular section connector ductility. About ductility, Eurocode 4 (2005) defines the shear connector as ductile if its characteristic slip capacity is at least $6 \mathrm{~mm}$. Thus, only the TP-S-NH-28MPa and TP-R-NH$28 \mathrm{MPa}$ connectors were not ductile.

a)

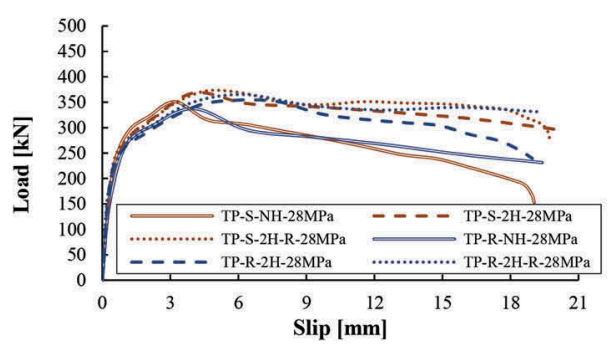

b)

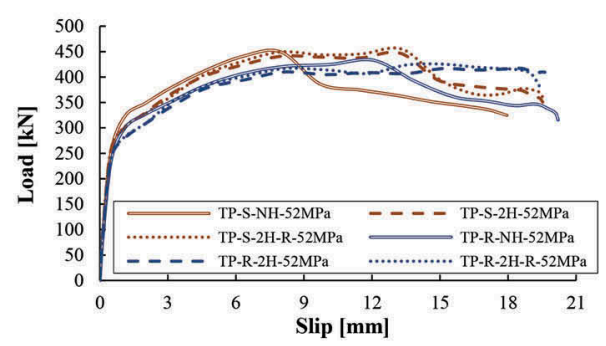

Figure 4. Load-slip curve for 28 and $52 \mathrm{MPa}$ models. a) TP-NH, TP-2H and TP-2H-R for $28 \mathrm{MPa}$, b) TP-NH, TP-2H and TP-2H-R for $52 \mathrm{MPa}$.

a)

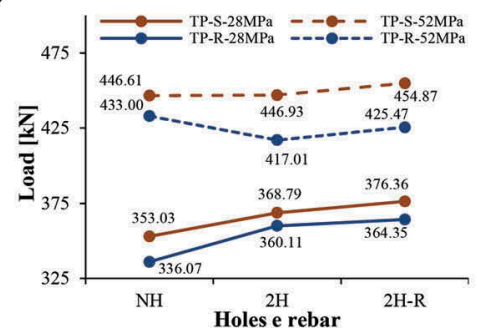

b)

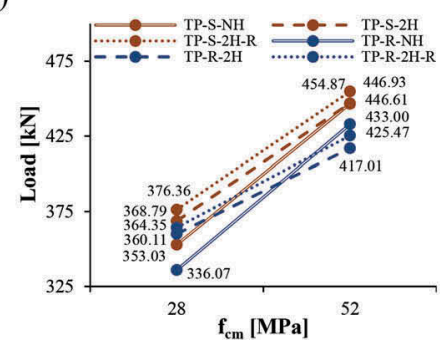

c)

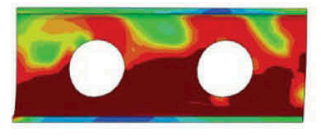

d)

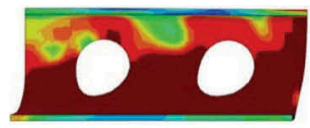

Figure 5. Influence of parameters and von mises stress distribution for TP-R-2H models. a) Influence of holes and rebar, b) Influence of concrete $f_{c m}$, c) TP-R-2H-28MPa, d) TP-R-2H-52MPa. 
Table 2. Push-out analyzes results.

\begin{tabular}{lllllllll}
\hline & $P$ & $P_{r k}$ & $K_{s}$ & $\delta_{u}$ & $\delta_{u k}$ & & & \\
\cline { 2 - 5 } Model & $\mathrm{kN}$ & $\mathrm{kN}$ & $\mathrm{kN} / \mathrm{mm}$ & $\mathrm{mm}$ & $\mathrm{mm}$ & Ductile? & Failure mode* \\
\hline TP-S-NH-28MPa & 353.03 & 317.72 & 572.20 & 4.55 & 4.10 & No & 3 \\
TP-S-NH-52MPa & 446.61 & 401.95 & 653,87 & 9.18 & 8.26 & Yes & 3 \\
TP-R-NH-28MPa & 336.07 & 302.46 & 534.15 & 5.88 & 5.29 & No & 3 \\
TP-R-NH-52MPa & 433.00 & 389.70 & 591.70 & 13.91 & 12.52 & Yes & 3 \\
TP-S-2H-28MPa & 368.79 & 331.91 & 646.23 & 12.35 & 11.12 & Yes & 1 \\
TP-S-2H-52MPa & 446.93 & 402.24 & 671.25 & 14.62 & 13.15 & Yes & 1 \\
TP-R-2H-28MPa & 360.11 & 324.10 & 595.81 & 11.03 & 9.93 & Yes & 3 \\
TP-R-2H-52MPa & 417.01 & 375.31 & 650.00 & $>20$ & $>20$ & Yes & 1 \\
TP-S-2H-R-28MPa & 376.36 & 338.73 & 616.24 & 17.83 & 16.05 & Yes & 1 \\
TP-S-2H-R-52MPa & 454.87 & 409.38 & 705.93 & 19.75 & 17.78 & Yes & 1 \\
TP-R-2H-R-28MPa & 364.35 & 327.92 & 604.10 & 9.64 & 8.68 & Yes & 3 \\
TP-R-2H-R-52MPa & 425.47 & 382.92 & 654.45 & 19.41 & 17.47 & Yes & 1 \\
\hline
\end{tabular}

* 1 -Failure of the connector. 2 - Local concrete crushing. 3 - Failure of the connectors associated with local concrete crushing.

All models with no holes (NH) had failure of the connectors associated with concrete crushing. All models with two holes $(2 \mathrm{H})$ and two holes and rebar $(2 \mathrm{H}-\mathrm{R})$ had failure of the shear connector with the exception of TP-R-2H-28MPa and TP-R-2H-R-28MPa which had similar failure mode to those with no holes. Figure $5 \mathrm{c}-\mathrm{d}$ shows the excessive yield of the TP-R-2H$28 \mathrm{MPa}$ and TP-R-2H-52MPa connectors.

\subsection{Tubular perfobond connector vs Perfobond connector}

The 70x70x3.6 mm square section was chosen for comparison with Perfobond connector due to its similar area. Comparing the tubular connector with the perfobond numeric connector model, it is evaluated that the tubular connector presents shear resistance $7.5 \%$ higher for the model with $f_{c m} 28 \mathrm{MPa}$, and $2.9 \%$ for $52 \mathrm{MPa}$. However, when compared to the experimental, the difference increases to $12 \%$ and $13 \%$ for $f_{c m} 28 \mathrm{MPa}$ and $52 \mathrm{MPa}$, respectively. Regarding slip capacity, the proposed connector presented $184 \%$ more than Perfobond when analyzed the numerical models of the Perfobond connector with $28 \mathrm{MPa}$ and $64 \%$ for $52 \mathrm{MPa}$ model.

The section chosen does not present such a superior resistant capacity when compared to Perfobond; however, it is important to mention that the peak load occurs for a higher level of slip and deformation, which is positive, considering that this is the proposal of this connector, being able to maintain the resistance while increasing its slip capacity, characterizing it as ductile.

\section{CONCLUSIONS}

The modelling validation indicated that numerical choices led to an adequate calibration in terms of ultimate load. The connector area variation led to a discrete increase in resistance. The presence of holes and rebar delayed the peak load, granting greater slip capacity to the connector. The increase of the concrete strength influenced the square section connector significantly in terms of increased shear resistance and the rectangular section connector ductility. Finally, the increase of the connector area, the use of the hole and the rebar and the increase of the concrete strength directly influenced the shear rigidity. When compared to Perfobond, the proposed connector presented a discretely superior resistance; however, it reached the desired ductility, presenting excellent post-peak slip capacity. Except for the two no holes connectors, all the proposed connectors could be considered ductile by Eurocode 4 (2005). Thus, it is important to enlarge the study considering other parameters and conditions, though this tubular connector proposal can be considered feasible. 


\section{ACKNOWLEDGEMENT}

The authors would like to thank CAPES (Finance code 001), CNPq (306042/2013-4; 305026/ 2017-8), FAPERJ and CERG for the financial support to this research program.

\section{REFERENCES}

Abaqus Documentation, Version 6.14, Dassault system, USA, 2010.

Bezerra, L. M.; Cavalcante, O. O.; Chater, L.; Bonilla, J. 2018. V-shaped shear connector for composite steel-concrete beam. Journal of Constructional Steel Research 150: 162-174.

CEB-FIP. 2010. Model code for concrete structures. International Federation for Structural Concrete (FIB), Switzerland.

Chen, Z.; Yuqing, L.; Shuangjie, Z.; Hino, S.; Yamaguchi, K. 2011. Experimental analysis of shear behavior of oval perfobond connector. International Conference on Tissue Engineering.

Eurocode 4, EN 1994- 1-1. 2005. Design of composite steel and concrete structures, Part. 1.1 general rules and rules for buildings. CEN, European Committee for Standardization.

Genikomsou, A. S.; Polak, M. A. 2015. Finite element analysis of punching shear of concrete slabs using damaged plasticity model in ABAQUS. Journal of Engineering Structures 98: 38-48.

Gu, J. C.; Liu, D.; Deng, W. Q.; Zhang, J. D. 2019. Experimental study on the shear resistance of a comb-type perfobond rib shear connector. Journal of Constructional Steel Research 158: 279-289.

Pavlovic, M. S. 2013. Resistance of bolted shear connectors in prefabricated steel-concrete composite decks. Doctoral Dissertation - Faculty of Civil Engineering, University of Belgrade, Belgrade.

Vianna, J. da C.; Costa-Neves, L. F.; Vellasco, P. C. G. da S.; de Andrade, S. A. L. 2009. Experimental assessment of Perfobond and T-Perfobond shear connectors' structural response. Journal of Constructional Steel Research 65: 408-421.

Yun, X.; Gardner, L. 2017. Stress-strain curves for hot-rolled steels. Journal of Constructional Steel Research 133: 36-46. 